\title{
EL III MARQUÉS DE MONTESCLAROS EN LA CORTE DE FELIPE IV: PRESIDENTE DEL CONSEJO DE HACIENDA Y CONSEJERO DE ESTADO (1571-1628)
}

\author{
Carlos J. De Carlos Morales \\ (Universidad Autónoma de Madrid-IULCE)
}

\section{RESUMEN}

Este trabajo presenta la trayectoria cortesana del III Marqués de Montesclaros. Tras repasar aspectos conocidos de su biografía y cargos de responsabilidad política en Sevilla y en las Indias hasta 1616, se centra en su actividad como consejero de Estado desde 1621 y sus relaciones con el conde duque de Olivares y, en particular, en su labor como presidente del Consejo de Hacienda de Castilla entre 1623 y 1626.

PALABRAS CLAVE: Juan de Luna y Mendoza; Montesclaros; Felipe IV; Olivares; Consejo de Hacienda.

\section{THE 3rd MARQUIS OF MONTESCLAROS IN THE COURT OF PHILIP IV: PRESIDENT OF THE COUNCIL OF FINANCES AND COUNSELLOR OF STATE (1571-1628)}

\begin{abstract}
This work presents the court career of the 3rd Marquis of Montesclaros. After reviewing known aspects of his biography and positions of political responsibility in Seville and the Indies until 1616, we focus on his activity as Counsellor of State since 1621 and his courtly relations with the Count Duke of Olivares; in particular, in his work as president of the Council of Finances between 1623 and 1626.
\end{abstract}

KEY WORDS: Juan de Luna and Mendoza; Montesclaros; Felipe IV; Olivares; Council of Finances. 
Este seminario sobre "Agentes de Gobierno en el Mundo Hispano (siglos XV-XVIII)" parece una ocasión propicia para exponer la trayectoria cortesana de don Juan Manuel de Mendoza y Luna, III marqués de Montesclaros y Castillo de Bayuela. Dadas las dimensiones de esta publicación no podemos extendernos en todas sus actividades, así que, en primer lugar, daremos un repaso a sus años más conocidos, que transcurrieron en Sevilla y en las Indias hasta 1616. A continuación, además de presentar algunas de sus propuestas y memoriales como consejero de Estado desde 1621 hasta su muerte en 1628 (ya en el ejercicio de la presidencia del Consejo de Aragón), nos centraremos en sus relaciones con el conde duque de Olivares en estos años cruciales del reinado de Felipe IV, en particular, nos detendremos en su labor como presidente del Consejo de Hacienda de Castilla entre 1623 y $1626^{1}$.

Hasta tiempos recientes, apenas hemos contado con estudios sobre el Consejo de Hacienda o sus presidentes durante el reinado de Felipe IV, con la excepción del breve e interesante trabajo de J. Fayard sobre José González, quien ocupó el cargo entre 1647 y $1652^{2}$. De hecho, desde el siglo XIX el análisis del gobierno de la Real Hacienda en tiempos de Felipe IV se ha planteado mayormente desde una visión normativa centrada en la promulgación de sucesivas ordenanzas $(1621,1635,1643,1651)$ y en la composición de correspondientes plantillas del Consejo y las contadurías mayores ${ }^{3}$. Se trataba de un enfoque que todavía se encuentra en algunas publicaciones aparecidas en las últimas décadas, que han mantenido unos presupuestos metodológicos formalistas, basados en la recopilación y descripción de diversos documentos e instrucciones de naturaleza jurídica ${ }^{4}$.

Desde otro punto de vista, recientes y originales publicaciones han permitido aportar una renovadora perspectiva social sobre determinados aspectos de la composición y funcionamiento del Consejo de Hacienda en tiempos de Felipe IV, precisamente a través del estudio de la labor de algunos presidentes y de la comisión

\footnotetext{
${ }^{1}$ Nuestra base documental se encuentra en el Archivo General de Simancas (AGS), la Biblioteca Nacional de España (BNE) y, sobre todo, en el Archivo de los Duques del Infantado (ADI), que hace unos años pudimos consultar gracias a la amabilidad de D. Luis Bueno. Ya hicimos uso de parte de esta documentación en los trabajos que citamos en nota 7.

2 Janine Fayard, "José González (1583?-1668), créature du comte-duc d'Olivares et conseiller de Philippe IV", en Hommage à Roland Mousnier: clientèles et fidélités en Europe à l'époque moderne, Y. Durand, ed. (París: Presses universitaires de France, 1981), 351-367. Ya se ocupó del Consejo, apuntando la importancia de sus presidentes Antonio Domínguez Ortiz, Politica y Hacienda de Felipe IV (Madrid: Ed. De Derecho financiero, 1960), 168-174.

${ }^{3}$ Francisco Gallardo Fernández, Origen, Progresos y Estado de las Rentas de la Corona de España, su Gobierno y Administración (Madrid: Imprenta Real, 1805), I, 38-68; y Tomás García-Cuenca Ariati, "El Consejo de Hacienda (1474-1803)", en La economía española al final del Antiguo Régimen. IV. Instituciones, ed. Miguel Artola (Madrid: Alianza, 1982), 441-451.

${ }^{4}$ Para el reinado de Felipe IV, Ildefonso Pulido Bueno, La Real Hacienda y sus oficiales de la Corte. Los Contadores mayores de Castilla en el Gobierno y Administración del patrimonio y Hacienda Real (Huelva: I. Pulido 2007), 377-392; José Luis Bermejo Cabrero, Organización hacendística de los Austrias a los Borbones: consejos, juntas y superintendencias (Madrid: U. Complutense, 2016), 42-48. Previamente, José María de Francisco Olmos, Los miembros del Consejo de Hacienda de Castilla en el siglo XVII (Madrid: Castellum, 1999), había ofrecido una recopilación de consejeros y documentos.
} 
de determinadas visitas: así, disponemos de un par de trabajos sobre la inspección que tuvo lugar a mediados del reinado, coincidiendo con la caída en desgracia de Olivares, y de otro interesante artículo en el que se recoge la visita que se realizó en la transición al reinado de Carlos $\mathrm{II}^{5}$. Es de esperar que tales investigaciones, realizadas por jóvenes historiadores, continúen y se conviertan en publicaciones de mayor dimensión, que nos permitan ahondar en el conocimiento del gobierno de la Real Hacienda durante el siglo XVII ${ }^{6}$.

Por nuestra parte, consideramos que la evolución y desarrollo jurisdiccional del Consejo de Hacienda puede concebirse como un escenario dinámico en el que se reflejaba la situación de las finanzas reales y las exigencias de gasto, las competencias y negociaciones con las Cortes de Castilla y con los hombres de negocios, y las relaciones de poder mantenidas en la corte a través de las prácticas de patronazgo y clientelismo, tal y como acabamos de mostrar en una reciente publicación. En este sentido, la presente aportación pretende contribuir a avanzar en el conocimiento de esta institución, tomando como eje el encumbramiento cortesano de su presidente en unos años cruciales, el marqués de Montesclaros, quien desempeño un cargo que hasta entonces parecía reservado a los letrados ya que contaba con pocos precedentes de nobles en su cabecera ${ }^{7}$.

\section{DE GUADALAJARA A LAS INDIAS: ASISTENTE EN SEVILLA Y VIRREY EN NUEVA ESPAÑA Y PERÚ}

Hijo póstumo del II marqués, desde su nacimiento en Guadalajara en enero de 1571 Montesclaros se mantuvo bajo el patronazgo de la rama familiar paterna de los poderosos duques del Infantado, encabezada entonces por el V duque, don Íñigo López de Mendoza y Mendoza, en cuyo palacio de Guadalajara se educó junto a poetas y escritores, y de la rama materna, pues era sobrino del adelantado mayor de Castilla don Martín de Padilla, conde de Santa Gadea, a quien acompañó en la

${ }^{5}$ Inés Gómez González, "Entre la corrupción y la venalidad: don Pedro Valle de la Cerda y la visita al Consejo de Hacienda de 1643", en Mérito, venalidad y corrupción en España y América: siglos XVII y XVIII, Pilar Ponce Leiva y Francisco Andújar Castillo, coords. (Valencia: Albatros, 2016), 235-250; Sébastien Malaprade, "Crédito y corrupción: la visita al Consejo de Hacienda de 1643”, Tiempos modernos 35 (2017): 363-387. Enrique Milán Coronado, "Controlar y reformar: la visita al Consejo de Hacienda de Lope de los Ríos (1664-1667)", Espacio, Tiempo y Forma. Serie IV. Historia Moderna 30 (2017): 181-210.

${ }^{6}$ Como ha sido el caso de Sébastien Malaprade, Des chatteaux en Espagne. Gouvernement des finances et mobilité sociale an XVII 'siècle (Limoges: Presses Universitaires de Limoges, 2018). Se ocupa de la visita en el capítulo 1 (33-63).

${ }^{7}$ Carlos Javier De Carlos Morales, "Entre visitas y ordenanzas: la reformación del Consejo de Hacienda, 1618-1626", en La Corte de Felipe IV (1621-1665): Reconfiguración de la Monarquía Católica, J. Martínez Millán y M. Rivero Rodríguez, coords. (Madrid: Polifemo 2017), II, 959-1002. También, ídem, "La política financiera de Felipe IV, 1621-1628”, en La Corte de Felipe IV (1621-1665), 1099-1212. 
jornada de Portugal como capitán de lanzas y en otras actividades militares en las galeras $^{8}$.

Ya desde entonces la búsqueda de honores, cargos e ingresos habría de ser una constante en el devenir de don Juan de Mendoza, dada la escasa riqueza de los señoríos recibidos con el título y el mayorazgo: apenas cuatrocientos vecinos distribuidos en las pobres tierras de la Alcarria alta y la sierra de San Vicente, en las actuales provincias de Guadalajara, Ávila y Toledo9. De esta manera, gracias al influjo familiar, tras solicitar el hábito de caballero de Santiago y superar las oportunas probanzas, al cabo de unos meses, el 13 de febrero de 1591, Felipe II le despachó el título que le reportaba honor y privilegios, sin que obtuviera alguna encomienda adicional que además añadiera renta a su casa ${ }^{10}$. Hubo de pasar un tiempo hasta que consiguió, acaso con la recomendación de don Juan de Acuña, VI conde de Buendía y su pariente por línea materna que servía el cargo de sumiller de corps desde 1585, el primer oficio cortesano, como gentilhombre de la boca de la Casa de Borgoña de Felipe II, en $1592^{11}$. Por otra parte, el marqués no tardó en contraer matrimonio, de acuerdo con las directrices de los duques del Infantado, con otra Mendoza, su prima doña Ana (en 1595).

La entronización de Felipe III representó una gran oportunidad para Montesclaros, gracias a que el Duque de Lerma había concertado el matrimonio de un hijo con una hija del duque del Infantado. Cuando este fue requerido por el nuevo rey para acompañarle a las celebraciones matrimoniales en Valencia, allí acudió con toda su familia y casa, incluidos los marqueses de Montesclaros ${ }^{12}$. Tras viajar a Barcelona, en las cortes catalanas Montesclaros recibió su primer encargo político, actuar como solicitador en nombre del rey ${ }^{13}$. Poco después, el 13 de septiembre de

\footnotetext{
${ }^{8}$ Una síntesis biográfica, Pilar Latasa Vassallo, "Mendoza y Luna, Juan”, en Diccionario Biográfico Español (Madrid: Real Academia de la Historia, 2009-2013), vol. XXXIV, 595-598, con las oportunas referencias bibliográficas de nobiliarios e historias de Guadalajara, que nos excusa de citarlas.

${ }^{9}$ Para la genealogía, mayorazgo y primeros años, Nicolás Cabrillana, "Un noble de la decadencia: el virrey Marqués de Montesclaros" (1571-1628)", Revista de Indias 115-118 (1969): 107-117. El título había sido otorgado por Carlos V a don Rodrigo, hermano del IV duque del Infantado, en agradecimiento por su comportamiento en la campaña de Túnez de 1535. Este primer marqués lo incorporó al mayorazgo que había recibido previamente, en 1529, con las villas de Castillo de Bayuela, Higuera de las Dueñas, la heredad de Montes Claros, y la dehesa de Bercina, a las que se añadieron la villa de Balconete y los lugares de Colmenar, El Vado y Cardoso de la Sierra. Para la Casa del Infantado, nos remitimos al reciente estudio de Adolfo Carrasco Martínez, El poder de la Sangre. Los duques del Infantado 1601-1841 (Madrid: Actas, 2010).

${ }^{10} \mathrm{El}$ expediente iniciado en octubre del año anterior, en AHN, Órdenes Militares, Santiago, pruebas de caballeros, caja 980, exp. 5181, puede consultarse digitalizado en pares.

${ }^{11}$ José Martínez Millán y Santiago Fernández Conti (dirs.), La monarquía de Felipe II: la Casa del Rey, 2 vols. (Madrid: Polifemo, 2005), II, 298.

12 Cristina de Arteaga, La Casa del Infantado, cabeza de los Mendoza, 2 vols. (Madrid: Duque del Infantado, 1940), I, 371-374. Así, la madre y viuda II marquesa de Montesclaros, doña Isabel Manrique de Padilla, que previamente había servido en la casa de la infanta Isabel Clara Eugenia, entró en la casa de la reina Margarita en 1599 como dueña de honor: Martínez Millán y Fernández Conti, $L a$ monarquia de Felipe II, II, 860 y 930.

${ }^{13}$ Luis Cabrera de Córdoba, Relaciones de las cosas sucedidas en la Corte de España desde 1599 hasta 1614 (Valladolid: Junta de Castilla y León, 1997 [facsímil]), 25.
} 
1600, Lerma dispuso para don Juan de Mendoza el importante nombramiento de asistente del rey en el ayuntamiento de Sevilla, además de gobernador de la milicia y tierra de Sevilla y su tierra y costas de Andalucía ${ }^{14}$.

La experiencia en Sevilla resultaría fundamental para su posterior carrera, además de los contactos que le reportó con el Consejo de Castilla y el Consejo de Indias, y con la nobleza andaluza. Como es sabido, a principios del siglo XVII era un auténtico emporio mercantil y financiero y la ciudad más poblada de España, con unos 150.000 habitantes de toda condición social y con los consiguientes problemas de orden público, abastecimiento, etc. Aquí, como representante regio, hubo de conocer los problemas militares de vigilancia costera, aprender el funcionamiento de instituciones como la Casa de Contratación, la Audiencia y el Consulado, implementar las decisiones políticas dictadas desde la corte y pactar con el regimiento y los veinticuatro las formas de recaudación de impuestos y arbitrios (sobre todo, el servicio de millones concedido por las Cortes en 1601), y negociar con los grandes mercaderes contribuciones de diversa índole que ayudaran a la financiación de las guerras entonces mantenidas con Inglaterra y Holanda.

Tal y como Teodoro Hampe advirtió, el cargo de asistente en Sevilla constituía el paso natural hacia un virreinato americano ${ }^{15}$. Además, durante los años en los que Montesclaros desempeñó esta responsabilidad en la ciudad hispalense aprovechó para reforzar sus lazos clientelares con Lerma, sabiendo que el valido reiteradamente utilizaba los nombramientos de Indias para favorecer a familiares y amigos $^{16}$. El marqués de Montesclaros no tardó en ser promocionado: el 14 de enero de 1603, el presidente del Consejo de Indias, Pablo de Laguna, le informaba de su designación como virrey de Nueva España ${ }^{17}$.

En sus años de gobierno en México, hasta noviembre de 1606, se enfrentó a la realización de obras públicas, el impulso a las actividades mineras, la reorganización hacendística, y la aplicación de la legislación sobre servicios y reducción de los indígenas. Al cabo, y tras salir indemne de serias acusaciones de corrupción, recibió nombramiento como virrey del Perú y se dirigió a Lima, en donde continuó con el desarrollo de las instituciones virreinales ya emprendido por sus antecesores, promovió reformas y recopilaciones legislativas, acentuó la explotación de los recursos mineros de azogue y plata, reforzó el control militar del

\footnotetext{
${ }^{14}$ Las instrucciones al marqués para ambos cargos, BNE, ms. 3207, fols. 593-604, en las que no entramos; comentadas por Cabrillana, "Un noble de la decadencia", 117-139, quien en su trabajo analiza sobre todo esta etapa sevillana gracias a diversa documentación localizada en este manuscrito, que actualmente puede consultarse digitalizado.

15 Teodoro Hampe Martínez, "Esbozo de una transferencia política: asistentes de Sevilla en el gobierno virreinal de México y Perú”, Historia mexicana 41-1 (1991), 49-81 (con referencias expresas al marqués de Montesclaros, 50, 54-56).

${ }^{16}$ Amorina Villareal Brasca, "Gestión política indiana en tiempos de Felipe III: a propósito del patronazgo del duque de Lerma (1598-1618)",Naveg@mérica 11 (2013):7-10.

${ }^{17} \mathrm{BNE}$, ms. 3207, fol. 679r, transcrita en Herrera Casado, El gobierno americano, 165, en la que se constata la relación clientelar entre ambos. Este cargo le reportó 20.000 ducados anuales de remuneración.
} 
territorio y la costa, y apoyó el reforzamiento de la evangelización de los indígena ${ }^{18}$. Fueron años de intensa actividad en los que en la corte virreinal Montesclaros actuó como un patrón favoreciendo según su criterio a sus amigos y servidores, algo que no debe entenderse en términos actuales de corrupción sino de clientelismo ${ }^{19}$. También, en este sentido, tenemos que interpretar la intensa vocación literaria del marqués y su deseo de rodearse de escritores y artistas, que ya había demostrado previamente y que hubo de desarrollar en un espacio cultural y de representación como la corte virreinal, en el que las fiestas públicas y religiosas brillaban y debían reflejar el poder político y social del alter ego del rey ${ }^{20}$.

\section{REFORMISMO Y REPUTACIÓN: CONSEJERO DE ESTADO DE FELIPE IV Y MIEMBRO DE DIVERSAS JUNTAS}

Tras ser relevado al frente del virreinato, a mediados de 1616 Montesclaros partió a España. Al llegar, hubo de pasar, en primer lugar, juicio de residencia por su actuación como virrey de Nueva España, por el que quedó absuelto de casi todos los cargos y fue simbólicamente sancionado por el Consejo de Indias a una multa de 600 ducados $^{21}$. Sin embargo, su juicio de residencia como virrey del Perú no resultó tan sencillo, pues su sucesor en el cargo, don Francisco de Borja y Aragón, príncipe de Esquilache, no tuvo reparos en apoyar las acusaciones contra Montesclaros, y el juez capitulante, Francisco de Vergara, actuó con sumo rigor en la proposición de las penas; sin embargo, la sentencia del Consejo de Indias exculpó a Montesclaros de la mayor parte de las acusaciones y le sancionó con una multa de 2.000 ducados $^{22}$.

\footnotetext{
18 Ya se acercó a sus años en ambos virreinatos, Antonio Herrera Casado, El gobierno americano del Marqués de Montesclaros (Guadalajara: Institución Provincial de Cultura "Marqués de Santillana", 1990). La estancia en el Perú (con una remuneración anual de 40.000 ducados) fue objeto de la excelente y extensa tesis doctoral, luego publicada, de Pilar Latasa Vassallo, Administración virreinal en el Perú: Gobierno del marqués de Montesclaros (1607-1615) (Madrid: Centro de Estudios Ramón Areces, 1997).

${ }^{19}$ Pilar Latasa Vassallo, "Poder y favor en la corte virreinal del Perú: los criados del marqués de Montesclaros (1607-1615)", Historica XXXVI.2 (2012): 49-84.

${ }^{20}$ La vocación y relaciones literarias de don Juan de Mendoza, en Aurelio Miró Quesada S., El primer virrey-poeta en América (Don Juan de Mendoza y Luna, Marque $\square$ s de Montesclaros) (Madrid: Gredos, 1962), también tratadas por Herrera Casado, El gobierno americano, 43-56. Más reciente, Sarissa Carneiro Araujo, "Encomio y cortesanía en el Virreinato del Perú: la «Canción real panegírica al marqués de Montesclaros» (1607) de Pedro de Oña", Hipogrifo 6.1 (2018): 31-51. Diversas consideraciones, Pilar Latasa Vassallo, "Transformaciones de una élite: el nuevo modelo de "nobleza de letras' en el Perú (1590-1621)”, en Élites urbanas en Hispanoamérica, Luisa Navarro García, coord. (Sevilla: Gredos, 2005), 413-433.

${ }^{21}$ Herrera Casado, El gobierno americano, 69-71, y 201-208, transcripción de la relación de cargos y la sentencia de septiembre de 1617 (localizados respectivamente en AGI, Gobierno, Indiferente General, leg. 37, y Escribanía de Cámara, 1185, fol. 1 y ss., ya publicados por Lewis Hanke, Los virreyes españoles en América durante el gobierno de la Casa de Austria (Madrid: Cátedra, 1978-1980) V, 296-303.

22 Herrera Casado, El gobierno americano, 98-100, y 236-245, transcripción de la comunicación de Esquilache y de la sentencia de junio de 1618 (localizada en AGI, Gobierno, Lima, 37, fols. 349-351v, y Escribanía de Cámara de Justicia, 1185, ya publicados por Lewis Hanke, Los virreyes españoles, II, 146156).
} 
Mientras tanto, el marqués presentó a Lerma un detallado memorial en solicitud de gratificaciones por sus servicios, poniendo como ejemplo una prolija relación de ejemplos que sus predecesores habían gozado. En junio de 1617 el valido se lo trasladó al Consejo de Indias y, fuera por sus juicios de residencia, por el viaje a Portugal, o la caída cortesana de Lerma, la respuesta se demoró hasta febrero de 1619: el Consejo de Indias estimó que sin duda el marqués merecía recompensas y nuevos nombramientos, pero el estado de la Real Hacienda impedía ofrecerle mayores mercedes ${ }^{23}$. Sin recibir respuesta positiva a sus solicitudes, durante un tiempo, pues, Montesclaros se ocupó de asuntos familiares, como contraer segundas nupcias con una sobrina también viuda, doña Luisa Antonia de Portocarrero y Mendoza, tal y como los duques del Infantado habían propuesto.

Como en el anterior cambio de reinado, el ascenso al trono de Felipe IV en marzo de 1621 resultó favorable para el marqués don Juan de Mendoza. Años antes, su regreso había coincidido con la llegada de otros personajes con experiencia en embajadas y virreinatos, que impulsaron un creciente ambiente cortesano de reformación y de recuperación de la política de reputación. Así, a pesar de su pasado lermista, gracias al apoyo de la Casa del Infantado y a la amistad que había sabido emprender con don Baltasar de Zúñiga y con Olivares, fue nombrado consejero de Estado y Guerra junto con el marqués de Aytona, el duque de Monteleón, y don Diego de Ibarra ${ }^{24}$.

Además, cuando el Consejo de Indias volvió a tratar la cuestión de las mercedes que podrían darse al marqués sugirió que se le otorgaran seis mil pesos de renta en repartimientos de indios, por dos vidas; además de acceder, Felipe IV le concedió ocho mil ducados de ayuda de costa, a satisfacer en cuatro años ${ }^{25}$. Poco después, Montesclaros obtuvo otra gratificación por mediación del duque del Infantado (que ejercía como mayordomo mayor de Felipe IV desde diciembre de 1622), pues a principios de agosto de 1623 el rey le concedió la cobranza de todos los atrasos como gentilhombre de la boca correspondientes a los años que había estado ausente de la corte, por importe de $2.282 .760 \mathrm{mrs}^{26}$.

Aunque no vamos a detenernos con detalle en los asuntos de Estado, sí vamos a aproximarnos a su participación en el Consejo gracias a una recopilación manuscrita de sus votos en algunas sesiones que nos permite glosar las

${ }^{23}$ Miró Quesada, El primer poeta, 215, 224-226, refiere el memorial del marqués y la respuesta del Consejo de Indias (localizados en AGI, Gobierno, Indiferente General, leg. 755), así como las posteriores vicisitudes.

${ }^{24}$ La noticia de su nombramiento, en Andrés de Almansa y Mendoza, Cartas y novedades de esta Corte y avisos recibidos de otras partes, 1621-1626 (Madrid: 1886), carta segunda, 20. En cuanto a su relación con Zúñiga y Olivares, ADI, Montesclaros, libro 31, fol. 50, carta de Zúñiga a Montesclaros, 2 de septiembre de 1622, y fol. 49, de Montesclaros a Olivares, 27 de mayo de 1622. Para el contexto cortesano, Rubén González Cuerva, Baltasar de Zúniga. Una encrucijada de la Monarquía Hispana (15611622) (Madrid: Polifemo, 2012).

25 Almansa y Mendoza, Cartas y novedades, carta octava, 726; Miró Quesada, Elprimer poeta, 226-228.

${ }^{26}$ AGP, Personal, caja 702, fol. 9. Nicolás Cabrillana, 148-149; José Martínez Millán y Eloy Hortal Muñoz, dirs., La corte de Felipe IV (1621-1665): reconfiguración de la Monarquía Católica (Madrid: Polifemo, 2015), tomo II, 1613. 
intervenciones que tuvo sobre los principales temas, en los que quedaron bien patentes los buenos conocimientos del marqués sobre las cuestiones que se trataban y su firme inclinación hacia una política de reputación ${ }^{27}$. Así, el 19 de junio de 1621, en su discurso sobre la Valtelina, exponía los motivos de la conveniencia de la conservación (derechos y promesa, estrategia común con el emperador), y aunque objetaba los costes que se derivarían concluía que había que asumirlos pues no cabía otra opción que apoyar, tal y como había hecho el duque de Feria, a los habitantes católicos y mantener el territorio. Poco después, el 29 de julio, se trataron "las cosas de Flandes después de la muerte del señor archiduque": exponía la imprevisión del suceso, alababa a Ambrosio Spínola pero advertía de su extranjería y de la necesidad de nombrar a alguien que colaborara con la Infanta, y de continuar con la guerra.

Dada la trascendencia de la implicación en la Guerra de los Treinta Años, este tema fue discutido en diversas ocasiones. Así, el 26 de marzo de 1623, tratando sobre el contenido de las cartas del conde de Oñate en las que se informaba de la situación en el Imperio y las ofertas del emperador a Baviera para incorporarse al colegio electoral, Montesclaros opinaba en contra y pensaba que el "camino más proporcionado" pasaba por la recuperación del conde palatino para la causa imperial mediante el matrimonio de su hijo con la segunda hija del emperador, tal y como había sugerido Carlos Colonna. Así mismo, si bien no se podía impedir el reforzamiento del ejército de la Liga Católica, convenía que las tropas de don Gonzalo de Córdoba tomaran posiciones en Alemania "metiéndole tan adentro". Poco después, el 6 de abril, de nuevo se discutía sobre las "cosas de Alemania y cartas del conde de Oñate", en donde la situación se había complicado notablemente con las actuaciones de Francia y la concesión de la dignidad electoral a Baviera. Proponía valorar el matrimonio del hijo del conde palatino con la sobrina del duque de Baviera, hija de su hermano y heredero, compensando también al primero con el palatinado inferior, lo que también satisfaría a Inglaterra. Además, convenía garantizar los 300.000 ducados mensuales de provisión para Flandes y mantener el esfuerzo financiero en Alemania ${ }^{28}$.

Transcurrido un tiempo, a 29 de mayo de 1625, opinaba sobre "la liga con el emperador y duque de Baviera" que había comunicado el embajador, mostrando sus móviles y consecuencias. Para el emperador se trataba de un modo de fortalecer su posición en el Imperio y para el duque de Baviera una forma para afianzar su "conservación", mientras que para Felipe IV ofrecía una buena ocasión para debilitar a los rebeldes holandeses. Comprobado el "prouecho", pasaba a valorar otras cuestiones: aclarar los objetivos y reparto de los gastos, incrementar los participantes con otros estados de Alemania ("que no se haga a título de religión"), obtener el

${ }^{27}$ BNE, ms. 18434, 56-76. No contamos con estudios específicos sobre el Consejo de Estado en estos años. Para la situación internacional, John H. Elliott, El conde-duque de Olivares. El político en una época de decadencia (Barcelona: Crítica, 1990), 77-103, 147-160; Manuel Rivero Rodríguez, El conde duque de Olivares. La búsqueda de la privanza perfecta (Madrid: Polifemo, 2018), 67-84, 121-127.

${ }^{28}$ No nos detenemos en la compleja situación de esta fase de la Guerra, tratada recientemente por Fernando Negredo del Cerro, La Guerra de los Treinta Años. Una visión desde la Monarquía Hispánica (Madrid: Síntesis, 2016), 89-116. 
apoyo del Papa y de otros príncipes de Italia, así como del rey de Polonia. En cuanto a los estados contrarios a la Liga, cabía esperar la oposición de Inglaterra, Dinamarca, Suecia, y los rebeldes de Flandes, además de Francia, Saboya y Venecia. Así, se trataría de una "liga y confederación" para "deffensa, offensa e interés" de los participantes.

Otro de los temas en los que Montesclaros intervino activamente fue el posible casamiento del príncipe de Gales con la Infanta. Aunque, en su opinión, el enlace fuera lícito y canónicamente aceptable, no había que desdeñar "el riesgo de la persona de la señora infanta, expuesta a la voluntad y fuerça de su marido no cathólico", y que no cabía asegurar la tolerancia respecto a los católicos ingleses. Para valorar el matrimonio había que considerar también la relación de Inglaterra con los enemigos de España, y en particular su apoyo de los holandeses. En suma, dado que "la mayor seguridad de los tratados consiste en la conueniencia de los contrayentes", no resultaba procedente confiar en el pretendiente inglés, que no ofrecía seguridades suficientes y que fácilmente podría mudar su actual deseo de amistad ${ }^{29}$.

También en el Consejo de Estado se discutieron cuestiones que se habían entregado al estudio de juntas específicas. Por ejemplo, el 20 de diciembre de 1621, se trató sobre "el arbitrio de la reformación" de las costumbres, y Montesclaros proponía diversas medidas para controlar el comportamiento y moral de la población de la corte, pues dadas las dificultades que encontraban los alcaldes para cumplir sus cometidos, convendría nombrar superintendentes y visitadores de calles y casas.

Posteriormente, en el verano de 1622, Felipe IV decidió constituir una Junta Grande de Reformación, encargada de estudiar las causas del profundo deterioro económico y social y los posibles remedios ${ }^{30}$. La importancia de sus cometidos puede colegirse de su composición, pues junto con Olivares se reunían el confesor Sotomayor, el Inquisidor general Pacheco, los presidentes de los consejos, y varios consejeros y procuradores de Cortes. El 1 de noviembre, Felipe IV comunicaba a Montesclaros su designación como miembro de la Junta Grande, y el marqués no se demoraba en responder, el día 7, opinando sobre "el estrago que en los reynos han hecho las mudanzas de los tiempos y otros accidentes": en un tono medidamente tacitista, valoraba la conveniencia de las pragmáticas de reformación de trajes y costumbres y, en particular, estimaba necesaria la fundación de los erarios que se trataba en Cortes, un proyecto sumamente interesante del que cabía esperar mucho aprovechamiento, si bien en cuanto a la dotación del fondo proponía "endulzar más

${ }^{29}$ BNE, ms. 18434, fols. 69-72. Para el "matrimonio inglés", Porfirio Sanz Camañes, Diplomacia hispano-inglesa en el siglo XVII: razón de Estado y relaciones de poder durante la Guerra de los Treinta Años, 1618 1648 (Cuenca: UCLM, 2002), 55-73. Las consultas de las juntas que se formaron en esta ocasión, en Dolores M. Sánchez, El Deber de consejo en el Estado moderno. Las Juntas "ad hoc" en España (1471-1665) (Madrid: Kalamo Libros, 1993) 160-164, con los pareceres de Montesclaros en Archivo General y Biblioteca del Ministerio de Asuntos Exteriores, ms. 243.

30 Ángel González Palencia, La Junta de Reformación (Madrid: Poncelix, 1935); J. H. Elliott, El condeduque de Olivares, 132-143. Juan Francisco Baltar Rodríguez, Las Juntas de Gobierno en la Monarquía Hispánica (siglos XVI-XVII) (Madrid: Centro de Estudios Políticos y constitucionales, 1998), 76-78, 175-187. 
el modo" para reducir la contribución del Reino y aplicar parte de las remesas de Indias ${ }^{31}$.

Así pues, además de ser uno de los cortesanos con más ascendiente en el gobierno de los asuntos de Estado y Guerra, el marqués se situó en muchas de las numerosas juntas que fueron creadas en los primeros años del reinado de Felipe IV, como forma ejecutiva de intervenir en asuntos que en teoría debían ser competencia de los Consejos ${ }^{32}$. Entre las más importantes, cabe señalar que fue nombrado presidente de la Junta de Comercio constituida en diciembre de 1621, y que funcionó hasta abril de 1625 con el encargo de dirigir la guerra económica contra las provincias rebeldes de los Países Bajos ${ }^{33}$. También perteneció a la Junta del Almirantazgo, creada en enero de 1625 para perseguir el contrabando, en cuyas sesiones Montesclaros dejó patente su opinión favorable al comercio proteccionista ${ }^{34}$.

Esta preeminente posición cortesana fue recogida por Andrés de Almansa, al referir su intervención en la "junta grande" en la que se reunieron, con Felipe IV, los más destacados miembros de los consejos de Estado y de Castilla, con objeto de tratar la forma de compeler a las ciudades a aceptar el servicio de los 72 millones de ducados:

y llegando a votar el Marqués de Montesclaros, presidente que es de Hacienda, y de los Consejos de Estado y Guerra, de la Cámara de su Majestad, segundo privado, quedaron todos admirados del sujeto, que tal cosa no se había visto, diciendo después del Cardenal Zapata que ni en Roma, ni en toda Europa, se había oído, ni visto sujeto tal ${ }^{35}$.

Aunque la simpatía que Andrés de Almansa y Mendoza habría de sentir por su pariente Montesclaros no garantizaba la ecuanimidad de la opinión expresada en esta carta de noticias cortesanas, sin duda ese apelativo que le dedicaba, segundo privado, revelaba una opinión común. Veamos ahora su actuación como presidente del Consejo de Hacienda y cómo devino su posición en la corte.

${ }^{31}$ El nombramiento, en BNE, ms. 6170, fols. 148-149, cédula firmada por el rey y remitida por el secretario de la Junta, Pedro de Contreras, a Montesclaros. De la respuesta existen varias copias: BNE, ms. 18434, fols. 62-63; Ibídem, ms. 1869, fols. 73. Para los erarios, en particular, Anne Dubet, Réformer les finances espagnoles au siècle d'or. Le projet V alle de la Cerda (Clermont Ferrand: Presses Universitaires Blaise Pascal, 2000), 302-314.

${ }^{32}$ Los billetes de Felipe IV ordenándole entrar en diversas juntas, ADI, Montesclaros, libro 31, fol. 25-41. Por ejemplo, también formó parte de la junta de obras y bosques desde el 19 de julio de 1623 hasta 1626.

${ }^{33}$ Eran además miembros de la junta Diego de Ibarra, Juan de Villela, el conde de Gondomar y Mendo da Mota. Véase Pere Molas Ribalta, "Instituciones y comercio en la España de Olivares", Studia Historica: Historia Moderna 5 (1987): 91-98; Baltar Rodríguez, Las Juntas de Gobierno, 208-216.

34 Ángel Alloza Aparicio, "La Junta del Almirantazgo y la lucha contra el contrabando, 1625-1643”, Espacio, Tiempo y forma. IV. Historia moderna 16 (2003): 217-254, y con más detalle, "Guerra económica y comercio europeo en España, 1624-1674: las grandes represalias y la lucha contra el contrabando", Hispania 119 (2005): 227-280.

35 Almansa y Mendoza, Cartas y novedades, 296. 


\section{PRESIDENTE DEL CONSEJO DE HACIENDA (1623-1626)}

El 19 de julio de 1623 Felipe IV nombró a don Juan de Mendoza y Luna nuevo presidente del Consejo de Hacienda ${ }^{36}$. La presencia de nobles en la presidencia de este Consejo había sido algo excepcional, pues solamente contaba con un precedente, don Bernardino de Velasco, conde de Salazar, entre 1618 y 1621. Por tanto, cabe preguntarse por las razones que impulsaron a Felipe IV a efectuar esta designación: ¿¿su confianza en la eficiencia del marqués y en su experiencia en cuestiones monetarias, tras su paso por los virreinatos de Indias? ¿O acaso pudo tratarse de una estrategia de Olivares para situar a Montesclaros en ocupaciones arduas y complicadas y frenar así su ascendente influjo cortesano? ¿A la inversa, se trataba de ofrecerle una vía de promoción? Tal y como ya había expresado, el principal deseo del marqués consistía en ser nombrado presidente del Consejo de Indias, por lo que el cargo recibido no satisfizo sus expectativas, como más adelante se encargaría de manifestar.

Ciertamente, la salida de su predecesor, Juan Roco Campofrío, había estado motivada por su falta de sintonía con Olivares respecto al matrimonio inglés y por su actitud al frente del Consejo de Hacienda, al poner en duda algunas de las órdenes de gasto dictadas por Felipe IV. De hecho, cabe advertir que al haber ido adquiriendo entidad institucional a través de visitas y ordenanzas, y bajo la sucesiva presidencia de letrados, el Consejo no se limitaba a actuar como un simple instrumento regio para el cumplimiento de los gastos y sus respuestas con frecuencia contrastaban con la premura exigida en la búsqueda de recursos para los gastos dinásticos.

Nada más acceder al cargo, Montesclaros se aplicó con diligencia en recabar información sobre la responsabilidad que acababa de asumir. En primer lugar, se apuntaba contra los cambios experimentados en el Consejo y en la Contaduría mayor de Cuentas como consecuencia de la cédula real de noviembre de 1621, ya que "La reformazión que se hizo en este Consejo fue de grandíssimo daño para su Magestad, porque hauiendo de mirar a entresacar lo dañado de él, a quitar lo insuficiente y ahorrar de costa, no se consiguió ninguno de estos tres fines, porque lo dañado se quedó y lo insuficiente, y se acreçentó la costa..." ${ }^{37}$.

Esta cuestión enlazaba, en segundo lugar, con los enfrentamientos existentes en el seno del Consejo, pues según se denunciaba "Los mayores desaçiertos que se hazen en el Consejo de Hazienda naçen de los odios y enemistades que tienen entre sí los consejeros, atendiendo en lo que se trata allí a solo contradezirse los unos a los otros...": así, se recomendaba que la principal virtud que debería tener el nuevo

\footnotetext{
${ }^{36}$ AHN, Consejos, libros de plaza, 725, fol. 97; AGS, EMR (Escribanía Mayor de Rentas), QC (Quitaciones de Corte), leg. 27, fols. 1256-1259.

37 ADI, Montesclaros, libro 56, fol. 59. El texto completo, en De Carlos Morales, "La reformación del Consejo de Hacienda", 992. También, ADI, Montesclaros, libro 56, fol. 46, sin fechar, "Relación del exercicio que tiene el Consejo de Hacienda, tribunales de oidores y quentas, y cada uno de los officios della para su administración y cobranza".
} 
presidente habría de ser la imparcialidad y el conocimiento de los consejeros, "de qué pie cojea cada uno para enmendalle o guardarse de él" 38 .

$\mathrm{Y}$, en tercer lugar, la situación se agravaba por el comportamiento de los mismos consejeros, tendente a la colusión con comisarios y administradores y propicio al descontrol de los gastos. En particular, se denunciaba la falta de control en los dispendios en las ceremonias cortesanas y fiestas taurinas, así como en las mercedes que se concedían ${ }^{39}$. Lo cierto es que los intentos de restringir los gastos se hicieron extensivos a los demás Consejos, y era una de las demostraciones de la opinión adversa que Olivares tenía en general sobre el sistema polisinodial y los letrados y su preferencia por el gobierno mediante juntas ocupadas por miembros de la nobleza ${ }^{40}$.

Pero la labor de Montesclaros al frente del Consejo de Hacienda no significó que este organismo mejorara su funcionamiento a ojos del valido. Con el paso de los meses parece que la situación solamente podría superarse mediante una nueva reforma institucional. Así en el Gran Memorial de diciembre de 1624, el autor, fuere quien fuere, no se recataba en trasladar al rey su pésimo juicio sobre el Consejo de Hacienda, el Tribunal de Oidores y la Contaduría de Cuentas, al tiempo que instaba a modificar su composición y organización ${ }^{41}$. Precisamente, por entonces, a finales de 1624, cuando el propio Consejo requirió una reforma de la sala de palacio en la que se reunían, argumentó que de esta manera al rey le resultaría más fácil vigilar secretamente sus reuniones ${ }^{42}$.

Sorprendentemente, de la posterior junta que fue impulsada por Olivares para proceder a una nueva reforma del Consejo de Hacienda quedó excluido el marqués de Montesclaros, que, mientras tanto, había estado enfrentándose a la falta de liquidez y al incremento de los gastos. A principios de julio de 1623, casi coincidiendo con su nombramiento como presidente del Consejo, se presentó ante las Cortes una detallada "Relación del estado y empeño en que se alla la Real Hacienda de Su Majestad", en la que se calculaba que los gastos anuales alcanzaban 8.500.000 ducados: para Flandes eran necesarios 3.800.000; para las armadas,

38 ADI, Montesclaros, libro 56, fol. 59. El párrafo se encuentra transcrito con algunos errores en John H. Elliott y F. de la Peña, Memoriales y cartas del conde duque de Olivares, 2 vols. (Madrid: Alfaguara 1978-80), I, 120, quienes lo atribuyeron a Baltasar Álamos de Barrientos. Por su parte, el marqués comenzó a actuar mediante la elección de personal cualificado en las vacantes: por ejemplo, sobre el escribano de las cartas de pago de la receptoría del Consejo, BL (British Library), Egerton, ms. 340, fols. 137, 18 diciembre de 1623, y fol. 135, sobre el fiscal, 16 de mayo de 1624.

39 ADI, Montesclaros, libro 48, no 12, Felipe IV a Montesclaros, el 24 de enero de 1624, y n ${ }^{\circ} 28$, el rey a Montesclaros, 12 de marzo de 1624.

40 Rivero Rodríguez, El conde duque de Olivares, 161-173, 243-250.

${ }^{41}$ Elliott y De la Peña, Memoriales y cartas, I, 84-85.

42 AGS, CJH (Consejo y Juntas de Hacienda), leg. 602, fajo 17, fol. 10, consulta de 19 de diciembre. Señalaba el Consejo la oscuridad del espacio en el que se ubicaba la mesa de reuniones y solicitaban reformar la sala, de manera que además de ganar luminosidad, "V. Md. terná de frente y a la vista a todos, que es más disposición para el intento que aora biene a estar sobre el presidente y consejeros que se sientan con él". Unos meses antes se había indicado al Consejo que controlara las peticiones de los "pretendientes": ADI, Montesclaros, libro 130, fol. 14, 30 de septiembre de 1624. 
1.200.000; para fronteras y presidios, 1.200.000; para las guardas, artillería y fábrica de armas, 250.000; para salarios de Consejos y audiencias, 300.000; para obras y bosques, 60.000; para el muelle de Gibraltar, 50.000; para gastos de embajadores, 150.000; para la despensa de las casas reales, 650.000; para carruajes y cosas extraordinarias, 140.000; para las tres guardas, capillas y demás gajes, 200.000; y para las galeras, 500.000 ducados $^{43}$.

En cuanto a los ingresos, las alcabalas y las rentas que se cobraban por arrendamiento y administración valían 5.351.169 ducados, pero estaban destinadas al pago de los intereses de los juros; el fruto de los maestrazgos se hallaban consignado a los Fugger hasta 1625, por 110.500 .000 maravedíes anuales; el servicio ordinario y extraordinario de las Cortes, valorado en 400.000 ducados, se encontraba empeñado hasta 1626, y una parte para 1627-1629; el servicio de millones estaba consignado y librado hasta fin de 1624 (2.000.000 anuales); las Tres Gracias, por importe de 1.400.000 ducados, también habían sido consignadas hasta 1625, incluido; la flota de Indias de 1622, que acababa de arribar, soportaba consignaciones por importe de 1.043.000 ducados, pero solamente montaba 903.000 ducados y faltarían 140.000; la flota de 1623 tenía ya consignados 470.000 ducados, y otro tanto la de 1624. Además, se adeudaban 800.000 ducados a los hombres de negocios por consignaciones fallidas, y había otras deudas acumuladas por atrasos, impagos, etc., que se elevaban hasta los seis millones.

Durante la presidencia de Montesclaros se consiguieron recursos financieros para superar las amenazas de los enemigos de la Monarquía, y fueron años de indudables éxitos militares. El año de 1624 comenzaba con un viaje del rey a Sevilla, emprendido en febrero, con el consiguiente coste de desplazamiento de la corte. Por ejemplo, a 26 de enero desde El Pardo, Felipe IV ordenó a Montesclaros que, "aunque por escussar costas y gastos así de mi hazienda (por el estado en que está) como a mis vasallos voy muy a la ligera y sin más criados de los que tengo en este sitio", debían proveerse los ordinarios y extraordinarios de la Casa real, y otros 50.000 ducados "para salir de aquí,", y continuaba: "y también tendréis dinero preuenido en las ciudades de Córdoba, Seuilla y Granada..." "44.

En el exterior, las campañas de Spínola en Flandes, con la preparación del asedio de Breda, estuvieron acompañadas de actuaciones bélicas del duque de Feria en Milán, la expedición para recuperar Bahía, en abril de 1625, así como del rechazo del ataque inglés a Cádiz meses después. En Alemania, las tropas de los Habsburgo

43 Actas de las Cortes de Castilla, vol. 39: Cortes convocadas en Madrid en el año de 1623 (Madrid: Establecimiento Tip. de Fortanet, 916), 15-22, y con detalle en ADI, Montesclaros, libro 26, fol. 10, "Relación sumaria de lo que su Magestad ha menester en cada un año para las prouisiones de su Real seruicio, dentro y fuera del Reyno, a poco más o menos, y del estado de la hazienda Real". Otra relación sumaria, en ibídem, $\mathrm{n}^{\circ} 6$, calculaba el total de ingresos en 9.775 .000 ducados, todos empeñados. Véase De Carlos Morales, "La política financiera", 1125-1130.

${ }^{44}$ ADI, Montesclaros, libro 48, fol. 14. Además, ordenaba que para hacer limosnas durante el viaje se reunieran otros 30.000 ducados (ibídem, fol. 15). 
también obtuvieron importantes avances. Pero nadie podía ignorar el creciente coste financiero de tales éxitos y la imposibilidad de soportarlo a medio plazo ${ }^{45}$.

Además, no parece que las relaciones de Montesclaros con los hombres de negocios genoveses que aportaban el grueso de los fondos en Flandes e Italia fueron precisamente cordiales. Entre sus documentos, destacan diversos memoriales que revelan que el marqués compartía la opinión comúnmente expresada en las Cortes y en otras instancias que criticaban con energía a los banqueros genoveses. En un extenso texto elaborado probablemente a comienzos del reinado de Felipe III por un oficial de la Casa de la Moneda de Toledo, pero entregado entonces para su estudio a Montesclaros, no se dudaba en vincular el descenso de la riqueza castellana con las actividades de los genoveses, a quienes comparaba con los zánganos, acusaba de haberse lucrado con todo "el crédito y el dinero, y por ello el mando y el señorío sobre todo... con que tienen corrompida la justicia y gouierno", y valoraba como motivo "de la destruición destos Reinos"46.

De hecho, aunque Montesclaros fuera el presidente, entre 1623 y 1626 las negociaciones para la firma de los asientos de provisiones generales fueron competencia directa que asumió el propio conde duque de Olivares. Sus relaciones con el marqués hubieron de deteriorarse pues, como hemos dicho, resulta sorprendente que fuera excluido de la junta para la reforma del Consejo de Hacienda 47. Al parecer, otro de los motivos de distanciamiento se encontró en los distintos criterios de ambos respecto a las consecuencias de la política de esfuerzo financiero y, en particular, respecto a la utilización del vellón, cuyas acuñaciones se habían reanudado en 1617 y continuaron hasta 1626; para entonces, en un cuarto de siglo se habían labrado, según algunas fuentes, más de 25 millones de ducados, con un beneficio neto de unos 17,4 millones (70\%).

Pero la Real Hacienda no asumía directamente las acuñaciones de moneda sino que el Consejo entregaba la importación del cobre y su labranza en consignación de los asientos. La moneda de vellón facilitó durante un tiempo la negociación crediticia y la monetización del déficit, pero la abundancia relativa del vellón respecto de la plata provocó el premio de la moneda de este metal, que se elevó hasta superar el $30 \%$ a comienzos de 1625: por ejemplo, por un real de plata, en lugar de $34 \mathrm{mrs}$. (valor oficial), se pagaban 40 maravedíes en vellón ${ }^{48}$. Por entonces ya se consideró la posibilidad de efectuar una devaluación forzosa de la moneda de vellón y el asunto fue tratado en el Consejo de Estado y en varias juntas, cuando el premio de la plata

${ }^{45}$ Con detalle, De Carlos Morales, "La política financiera", 1134-1155.

46 ADI, Montesclaros, libro 130, fol. 21: "Donde comenzó la pobreça y necesidad de estos Reynos fue la venida de Ginoveses en España, que a nuestros pecados en ella entraron porque con sus tratos, vidas y costumbres no se saue que cosa buena ni virtuosa ayan edificado, y sáuese que con sus logros y viçiosa vivienda lo tienen todo asolado y estragado, ni se hallará que con dinero suyo ayan hecho socorro a V. Md. ni a otro, porque de su tierra a esta no han traído más que seis personas cargadas de tan malos arbitrios que an chupado toda la riqueza...". Puede verse en De Carlos Morales, "La política financiera", 1119-1121.

${ }^{47}$ De Carlos Morales, "Entre visitas y ordenanzas", 993-997.

48 Sobre este tema, nota 45. 
se había elevado al $50 \%$. El voto del marqués, tras repasar con tono crítico todas las medidas financieras emprendidas desde 1621, fue contrario a la devaluación, pues además de apreciar su efecto negativo sobre las haciendas particulares creía que el problema fundamental era la escasez de plata respecto de la demanda financiera de la monarquía, debido al contrabando y al fraude en Sevilla, a las licencias de saca, y al aumento de los gastos militares ${ }^{49}$. La determinación entonces adoptada por el Consejo de Castilla a través de la pragmática del 8 de marzo de 1625 consistió en establecer un límite legal del premio del $10 \%$.

\section{MÁS SERVICIOS EN LA CORTE DE FELIPE IV COMO CONSEJERO DE ESTADO Y PRESIDENTE DEL CONSEJO DE ARAGÓN}

Con el paso de los meses las relaciones entre Olivares y Montesclaros fueron deteriorándose debido a la desconfianza del valido. En consecuencia, a comienzos de 1626 Montesclaros pidió ser exonerado de la presidencia del Consejo de Hacienda, en la que en febrero fue relevado por Baltasar Gilimón de la Mota. La excusa que encontró el marqués para justificar su salida voluntaria del Consejo de Hacienda fue que debía cumplir con el encargo de acompañar a Felipe IV en su viaje a la Corona de Aragón como miembro de su Casa real $^{50}$. Por entonces, según decía Vera y Figueroa al duque de Alba, "es de saber que el marqués de Montesclaros espera también su pedestal", ya que anhelaba ser nombrado presidente o al menos tesorero general del Consejo de Aragón; sin embargo, recibió mero título de consejero, lo que consideró un agravio ${ }^{51}$.

Al parecer, como muestra de su frustración, hizo un breve retiro a sus estados. Pero de regreso, en agosto, mantuvo un encuentro privado con Olivares que dio lugar a una breve pero intensa relación epistolar. En su primera misiva, Montesclaros, a 15 de agosto, se dirigía a Olivares para aclararle algunos aspectos de dicha conversación y reiteraba que en su ánimo no había interés personal sino ofrecerle el mejor consejo que pudiera servirle, y le recordaba su trayectoria en la corte: entró en el Consejo de Estado al mismo tiempo que Diego de Ibarra, quien recibió diez o doce mil ducados de renta, mientras que él lo hizo "sin un real entonces" y además otros consejeros que posteriormente habían entrado enseguida habían mejorado la plaza. En cuanto a la merced de 6.000 ducados de renta que después había recibido, afirmaba que resultaba inferior a la que otros virreyes habían obtenido, y lo mismo podía decirse de así los 8.000 ducados de ayuda de costa. Y cuando después fue nombrado para ocupar la presidencia del Consejo de Hacienda, "la calidad de esta merced se muestra en hauer escogido por mexor dexarla sin otro trueque que exercerla con tal riesgo" e, incluso, no tenía reparos en señalar que

49 ADI, Montesclaros, libro 130, fols. 32 y 33, arbitrios propuestos desde 1617 para aumentar la plata disponible, $\mathrm{y}^{\mathrm{o}} 36$, memorial del marqués de Montesclaros, borrador de su voto en el Consejo de Estado, en 1625, en BNE, ms. 18434, fols. 77-81.

${ }^{50}$ Diversos encargos recibidos de Felipe IV durante este viaje, ADI, Montesclaros, libro 130, fol. 44 y 45 . Al parecer, había sido promocionado a gentilhombre de cámara.

${ }^{51}$ Citado por Cabrillana, "Un noble en decadencia", 149. 
después de la reforma del Consejo realizada en febrero de 1626 a otros consejeros que tuvieron que dejar el cargo se habían dado mercedes y a él no. Por otra parte, haber recibido llave de la cámara del rey le había ocasionado en la jornada de Aragón "indignidades". Así, afirmaba, "En desquento de todo, e seruido y trauajado lo mejor que alcançó mi sauer, algunas vezes se a hallado V. Exc. satisfecho y ha querido que lo supieran otros...", y concluía que "le suplico no me mire como acreedor pues estoy tan pagado y reconocido" 52 .

En su respuesta Olivares mostró su malestar con la actitud de Montesclaros, utilizó un tono duro y diversos comentarios cínicos (decía encontrarse sin "aliento", o se lamentaba sobre las mercedes que Montesclaros había o no recibido excusándose al afirmar que "no estoy en estado de azertar aun cosas mucho más fáciles, y no es disculpa, pero es causa de compasión"), le puso ejemplos que demostraban que sus quejas eran injustificadas, como que había sido el primer virrey de Indias en entrar en el Consejo de Estado (mientras que Diego de Ibarra y el marqués de Aytona le aventajaban en embajadas y otros servicios), y le recriminaba sus comentarios sobre la presidencia del Consejo de Hacienda, la llave de la cámara, y su "ambición", que le había impedido reconocer todas las muchas muestras de gracia que había recibido ${ }^{53}$.

Dado que no había obtenido, a su juicio, aquellos nombramientos y recompensas que creía merecer, la decepción de Montesclaros hubo de ser profunda, más aún ya que a ojos de la corte había quedado patente que había sido preterido mientras que otros personajes habían ya obtenido mejor suerte. En un curioso memorial que se encuentra junto a las dos cartas anteriores se referían las causas de la "nota y descommodidad que a padecido", por lo que la merced que se le hiciere debía ser de suficiente calidad para compensar "su poca fortuna", una vez que no había sido nombrado para "bacantes de todo género, virreinatos, presidencias, embajadas, encomiendas..." que su Majestad había dispuesto a lo largo del año ${ }^{54}$. Podemos colegir que Montesclaros, como otros nobles de ramas segundonas, padecía agudos problemas de liquidez, por una parte, y la aspiración a la Grandeza, por otra.

Al cabo, Montesclaros volvió a sus ocupaciones cortesanas y, en particular, a las reuniones del Consejo de Estado. Así, en septiembre de 1626 el marqués se integró en la junta que, bajo la dirección del valido, recibió la responsabilidad de estudiar la posición y los posibles destinos de los hermanos del rey, los infantes Fernando y Carlos ${ }^{55}$. Sus relaciones cortesanas con Olivares representaban ese doble juego de confianza y recelo que desde años antes mantenían. A 27 de abril de 1627 el conde duque le escribía desde Aranjuez para agradecerle "que esté bueno y contento, y que ni le cansen juntas ni consejos, ni le inquieten cuidados, así ha de ser, y fiar mucho en Dios para viuir larga y descansadamente libre de vissiones..." ${ }^{\text {. }}$. Lo cierto

\footnotetext{
52 ADI, Montesclaros, libro 31, fol. 51, a 15 de agosto de 1626.

${ }^{53}$ ADI, Montesclaros, libro 31, fol. 52, a 24 de agosto.

54 ADI, Montesclaros, libro 31, fol. 55.

55 ADI, Montesclaros, libro 130, fol. 3. Véase, Rivero Rodríguez, El conde duque de Olivares, 192-199.

56 ADI, Montesclaros, libro 31, fol. 57.
} 
es que Montesclaros no había cesado de reiterar sus peticiones, y Olivares no se recataba en lanzarle algún rehilete cuando continuaba comentando la ubicación del marqués en las juntas: "Poco mortificado está V.S., pues en presencia de tres cardenales y viendo ceder al señor presidente de Castilla se acuerda de lugares y preçedencias del vicecanciller de Aragón; no piense V.S. en cuidados ajenos que es enfermedad de desaprouechados". Y es que, meses antes, Montesclaros había sido designado tesorero general del Consejo de Aragón, y, al fin, a mediados de 1627 recibió el nombramiento como presidente de este Consejo ${ }^{57}$. Quizás se le había hecho poco, cuando en abril se había rumoreado que podría ser el sucesor de don Francisco de Contreras en la presidencia del Consejo de Castilla ${ }^{58}$.

Aunque no viera todas sus ambiciones satisfechas, Montesclaros al menos había afianzado su lugar en la corte como uno de los hombres de confianza del valido, si bien mantendría en todo momento su propio criterio y no dejaran de expresarse sus discrepancias. Por ejemplo, entre julio y octubre de 1627 el marqués así lo demostró con ocasión de la grave enfermedad padecida por Felipe IV, para la que redactó un proyecto de regencia que estaría dirigido por la reina y secundado por los infantes, y de un curioso memorial sobre la actitud de un consejero de Estado y noble en ese caso ${ }^{59}$. En ambos documentos su postura no deja de ser finamente crítica con las prácticas del valido, o al menos se planteaba una salida para que, en caso de la muerte del rey, al menos había preservado su propio comportamiento.

Resulta patente que Montesclaros precisaba del valido para medrar y que Olivares no quería ni podía prescindir del apoyo de la Casa del Infantado, y mucho menos en aquella grave crisis cortesana acaecida entre el verano y el otoño de 1627. De hecho, aunque no adquiera la Grandeza, Montesclaros también se preocupó de conservar su herencia, por lo que como no tenía hijos varones legítimos concertó el matrimonio de su única hija legítima, Isabel de Mendoza y Portocarrero, con su primo, el heredero al ducado del Infantado ${ }^{60}$.

Además de ejercer como presidente del Consejo de Aragón ${ }^{61}$, Montesclaros se mantuvo como consejero de Estado y fue requerido, en particular, para opinar sobre un tema que dominaba con solvencia: la situación monetaria y la forma de conseguir la reducción del premio de la plata. A comienzos de 1628 Felipe IV estaba ya convencido de la necesidad de efectuar una devaluación de la moneda de vellón, pero la cuestión estribaba en determinar la magnitud del descuento. Según diversos cálculos, antes de que comenzara la labor de vellón existía una masa monetaria de

${ }^{57}$ Información al respecto, así como de su participación en diversas juntas, Álvaro Sánchez Durán, "Gobierno y redes clientelares en la Monarquía Hispánica de Felipe IV: el protonotario Jerónimo de Villanueva y la Corona de Aragón (1626-1643)", Pedralbes 36 (2016): 249-299. Fue el primer presidente no natural, tras la reforma del Consejo efectuada unos años antes.

${ }^{58}$ Elliott, El Conde-Duque, 310.

${ }^{59}$ ADI, Montesclaros, libro 130, fols. 1 y 2, analizados por Santiago Martínez Hernández, "Los más infames y bajos traidores...: el desafío aristocrático al proyecto olivarista de regencia durante la enfermedad de Felipe IV (1627)", Investigaciones históricas 14 (2014): 47-80, y por Rivero Rodriguez, El conde duque de Olivares, 199-202.

${ }^{60}$ Latasa Vasallo, Administración virreinal, 597. La muerte de la heredera en 1629 frustró el concierto.

${ }^{61}$ Véase la documentación, ADI, Montesclaros, libro 33, sobre la que no podemos extendernos. 
seis millones de ducados, que desde principios del siglo XVII había aumentado hasta alcanzar hacia 1628 los cuarenta millones. Un memorial de Alexandre Linde que estuvo en manos de Montesclaros, advertía que el remedio debía encontrarse en la restitución del valor original de la moneda de cobre, que debería ejecutarse de una vez, con el efecto de recuperar la recaudación de las rentas reales, evitar la salida de metales preciosos, y reactivar el comercio ${ }^{62}$.

Por su parte, el marqués de Montesclaros, apelando a la "razón de estado" se mostró también partidario de la devaluación monetaria pero evitando propuestas tan agresivas, que podrían poner en peligro las provisiones y que además significarían un grave perjuicio para los vasallos del rey: las posibilidades oscilaban entre un descuento del $25 \%$, que juzgaba insuficiente, y uno del $75 \%$, que podría ser excesivo por "la violencia de un golpe" sobre el comercio ${ }^{63}$. Por consiguiente, Montesclaros se decantaba por la solución intermedia, la devaluación del 50 \%, al tiempo que inclúa una interesante reflexión sobre las cualidades del vellón en los intercambios, en la que mostraba su sorpresa respecto a su utilidad como moneda fiduciaria en la época de la moneda metálica:

La moneda de vellón es cosecha de nuestra tierra que no sale para otra ninguna, de que nos maravillamos que valga poco en tiempo de la abundancia y que el que trueca por ella sus mercaderías o maniobras fabricadas de materiales y géneros que trujo de fuera suba el precio a medida de la estimación que nosotros hazemos de la moneda en que le pagamos, fuera de que en esta regla o pérdida entran también los estrangeros que meten esta moneda, porque mientras menos la estimamos menos ganan ellos en traérnosla, y así tendría fin su granjería cuando el desprecio del vellón respecto de los trueques y compras le viniese a dejar en solo el valor intrínseco...

La opinión de Montesclaros fue seguida por Felipe IV y el 7 de agosto de 1628 firmó una pragmática que ordenaba la "reduzión de la moneda de vellón a mitad de su precio", y que consiguió bajar el premio de la plata del 80 al $10 \%{ }^{64}$. Este habría de ser uno de los últimos servicios de don Juan de Mendoza, pues falleció en Madrid el 9 de octubre de $1628^{65}$.

62 ADI, Montesclaros, libro 26, fol. 13, memorial de Alexandre Lindo. Ya me ocupé de esta cuestión en De Carlos Morales, "La política financiera de Felipe IV", 1206-1211.

${ }^{63}$ ADI, Montesclaros, libro 26, fol. 16, memorial del marqués fechado el 9 de julio de 1628.

${ }^{64}$ BNE, ms. 7971, fols. 168-170.

${ }^{65}$ AHPNM (Archivo Histórico de Protocolos Notariales de Madrid), Pr. 2352, fols. 438r-441v: testamento otorgado en Madrid, 8 de octubre de 1628 ante el escribano Diego Ruiz de Tapia, comentado por Miró Quesada: 236-241. 


\section{REFERENCIAS BIBLIOGRÁFICAS}

Ángel Alloza Aparicio, "La Junta del Almirantazgo y la lucha contra el contrabando, 1625-1643”, Espacio, Tiempo y forma. IV. Historia moderna 16 (2003): 217-254.

---“Guerra económica y comercio europeo en España, 1624-1674: las grandes represalias y la lucha contra el contrabando", Hispania 119 (2005): 227-280.

Andrés Almansa y Mendoza, Cartas y novedades de esta Corte y avisos recibidos de otras partes, 1621-1626 (Madrid: 1886).

Cristina de Arteaga, La Casa del Infantado, cabeza de los Mendoza, 2 vols. (Madrid: Duque del Infantado, 1940).

José Francisco Baltar Rodríguez, Las Juntas de Gobierno en la Monarquia Hispánica (siglos XVI-XVII) (Madrid: Centro de Estudios Políticos y constitucionales, 1998).

José Luis Bermejo Cabrero, Organización hacendística de los Austrias a los Borbones: consejos, juntas y superintendencias (Madrid: U. Complutense, 2016).

Luis Cabrera de Córdoba, Relaciones de las cosas sucedidas en la Corte de España desde 1599 hasta 1614 (Valladolid: Junta de Castilla y León, 1997 [facsímil]).

Nicolás Cabrillana, "Un noble de la decadencia: el virrey Marqués de Montesclaros (1571-1628)", Revista de Indias 115-118 (1969): 107-150.

Carlos Javier de Carlos Morales, "Entre visitas y ordenanzas: la reformación del Consejo de Hacienda, 1618-1626", en La Corte de Felipe IV (1621-1665): reconfiguración de la Monarquía Católica, J. Martínez Millán y M. Rivero Rodríguez, coords. (Madrid: Polifemo 2017), II: 959-1002.

---“La política financiera de Felipe IV, 1621-1628”, en La Corte de Felipe IV (16211665: 1099-1212.

Sarissa Carneiro Araujo, "Encomio y cortesanía en el Virreinato del Perú: la «Canción real panegírica al marqués de Montesclaros» (1607) de Pedro de Oña”, Hipogrifo 6.1 (2018): 31-51.

Adolfo Carrasco Martínez, El poder de la Sangre. Los duques del Infantado 1601-1841 (Madrid: Actas, 2010).

Antonio Domínguez Ortiz, Política y Hacienda de Felipe IV (Madrid: Ed. Del derecho financiero, 1960). 
Anne Dubet, Réformer les finances espagnoles au siècle d'or. Le projet Valle de la Cerda (Clermont Ferrand: Presses Universitaires Blaise Pascal, 2000).

John H. Elliott, El conde-duque de Olivares. El político en una época de decadencia (Barcelona: Crítica, 1990).

John H. Elliott y José F. de la Peña, Memoriales y cartas del conde duque de Olivares, 2 vols. (Madrid: Alfaguara, 1978-80).

Janinne Fayard, "José González (1583?-1668), créature du comte-duc d'Olivares et conseiller de Philippe IV", en Hommage à Roland Mousnier: clientèles et fidélités en Europe à l'époque moderne, Y. Durand, ed. (París: Presses universitaires de France, 1981), 351-367.

José María Francisco Olmos, Los miembros del Consejo de Hacienda de Castilla en el siglo XVII (Madrid: Castellum, 1999).

Francisco Gallardo Fernández, Origen, Progresos y Estado de las Rentas de la Corona de España, su Gobierno y Administración, vol. I (Madrid: Imprenta Real, 1805).

Tomás García-Cuenca Ariati, "El Consejo de Hacienda (1474-1803)", en La economía española al final del Antiguo Régimen. IV. Instituciones, ed. M. Artola (Madrid: Alianza, 1982), 441-451.

Inés Gómez González, "Entre la corrupción y la venalidad: don Pedro Valle de la Cerda y la visita al Consejo de Hacienda de 1643", en Mérito, venalidad y corrupción en España y América: siglos XVII y XVIII, en Pilar Ponce Leiva y Francisco Andújar Castillo, coords. (Valencia: Albatros, 2016), 235-250.

Rubén González Cuerva, Baltasar de Zúniga. Una encrucijada de la Monarquía Hispana. (1561-1622) (Madrid: Polifemo, 2012).

Ángel González Palencia, La Junta de Reformación (Madrid: Poncelix, 1935).

Teodoro Hampe Martínez, "Esbozo de una transferencia política: asistentes de Sevilla en el gobierno virreinal de México y Perú", Historia mexicana 41-1 (1991): 49-81.

Lewis Hanke, Los virreyes españoles en América durante el gobierno de la Casa de Austria, V (Madrid: Cátedra 1978-1980).

Antonio Herrera Casado, El gobierno americano del Marqués de Montesclaros (Guadalajara: Institución Provincial de Cultura "Marqués de Santillana", 1990). 
Pilar Latasa Vassallo, Administración virreinal en el Perú: Gobierno del marqués de Montesclaros (1607-1615) (Madrid: Centro de Estudios Ramón Areces, 1997).

---“Transformaciones de una élite: el nuevo modelo de 'nobleza de letras' en el Perú (1590-1621)", en Luisa Navarro García, coord., Élites urbanas en Hispanoamérica (Sevilla: Gredos, 2005), 413-433.

---"Poder y favor en la corte virreinal del Perú: los criados del marqués de Montesclaros (1607-1615)", Historica XXXVI.2 (2012): 49-84.

---“Mendoza y Luna, Juan”, en Diccionario Biográfico Español, vol. XXXIV (Madrid: Real Academia de la Historia, 2009-2013), 595-598.

Sebastián Malaprade, "Crédito y corrupción: la visita al Consejo de Hacienda de 1643”, Tiempos modernos 35 (2017): 363-387.

Sébastien Malaprade, Des châteaux en Espagne. Gouvernement des finances et mobilité sociale au XVII 'eiècle (Limoges: Presses Universitaires de Limoges, 2018).

Santiago Martínez Hernández, "Los más infames y bajos traidores...: el desafío aristocrático al proyecto olivarista de regencia durante la enfermedad de Felipe IV (1627)", Investigaciones históricas 14 (2014): 47-80.

José Martínez Millán y Santiago Fernández Conti (dirs.): La monarquía de Felipe II: la Casa del Rey, 2 vols. (Madrid: MAPFRE -Tavera, 2005).

Martínez Millán, José, y Hortal Muñoz, Eloy (dirs.): La corte de Felipe IV (1621-1665): reconfiguración de la Monarquía Católica. Tomo II (Madrid: Polifemo, 2015).

Milán Coronado, Enrique: "Controlar y reformar: la visita al Consejo de Hacienda de Lope de los Ríos (1664-1667)", Espacio, Tiempo y Forma. Serie IV. Historia Moderna 30 (2017): 181-210.

Aurelio Miró Quesada S., El primer virrey-poeta en Ame $\square$ rica (Don Juan de Mendoza y Luna, Marque $\square$ s de Montesclaros) (Madrid: Gredos, 1962).

Pere Molas Ribalta, "Instituciones y comercio en la España de Olivares", Studia Historica: Historia Moderna 5 (1987): 91-98.

Fernando Negredo del Cerro, La Guerra de los Treinta Años. Una visión desde la Monarquia Hispánica (Madrid: Síntesis, 2016). 
Ildefonso Pulido Bueno, La Real Hacienda y sus oficiales de la Corte. Los Contadores mayores de Castilla en el Gobierno y Administración del patrimonio y Hacienda Real (Huelva: I. Pulido, 2007).

Manuel Rivero Rodríguez, El conde duque de Olivares. La búsqueda de la privanza perfecta (Madrid: Polifemo, 2018).

Dolores M. Sánchez, El Deber de consejo en el Estado moderno. Las Juntas "ad hoc" en España (1471-1665) (Madrid: Kalamo, 1993).

Álvaro Sánchez Durán, “Gobierno y redes clientelares en la Monarquía Hispánica de Felipe IV: el protonotario Jerónimo de Villanueva y la Corona de Aragón (1626-1643)", Pedralbes 36 (2016): 249-299.

Porfirio Sanz Camañes, Diplomacia hispano-inglesa en el siglo XVII: razón de Estado y relaciones de poder durante la Guerra de los Treinta Años, 1618-1648 (Cuenca: UCLM, 2002).

Amorina Villareal Brasca, "Gestión política indiana en tiempos de Felipe III: a propósito del patronazgo del duque de Lerma (1598-1618)”, Naveg@mérica 11 (2013): 1-15.

Recibido: 9 de agosto de 2018 Aprobado: 14 de marzo de 2019 